\title{
USO DE IMAGENS ORBITAIS COMO BASE DE DADOS PARA PROJETOS DE REFORMA AGRÁRIA ${ }^{1}$
}

\author{
Marina de Fátima Vilela ${ }^{2}$, Vicente Paulo Soares ${ }^{3}$, Roberto Engel Aduan², Elpídio Inácio Fernandes Filho \\ Ricardo de Araújo Pereira ${ }^{6}$ Carlos Antônio Alvares Soares Ribeiro ${ }^{3}$
}

\begin{abstract}
RESUMO - Análises técnica e econômica foram realizadas em imagens dos sensores IKONOS, TM/Landsat 5, ETM+/Landsat 7 e CCD/CBERS, objetivando a verificação da viabilidade destas como base de dados em projetos de reforma agrária. Essas análises efetuadas e a situação de mercado indicaram que a imagem IKONOS apresenta excelente desempenho técnico, mas o custo de aquisição inviabiliza sua utilização como base de dados para a reforma agrária. A imagem do Landsat 7, com baixo custo de aquisição, apresentou grande viabilidade técnica para fins de reforma agrária. No entanto, a perda do contato com a plataforma Landsat 7 inviabilizou a compra de novas imagens do sensor ETM+. A imagem CCD/CBERS apresentou a segunda maior similaridade com a verdade de campo e o menor índice Kappa para a classificação. Apesar do baixo índice de exatidão para a classificação, as análises de custo, o lançamento do CBERS-2 e a possibilidade de correção dos problemas de radiometria podem tornar as imagens da plataforma CBERS-2 concorrentes de peso no mercado e, ainda, preencher a lacuna deixada pela perda do Landsat 7. A imagem do Landsat 5 apresentou o mais baixo desempenho técnico nas análises efetuadas. Entretanto, seu potencial como base de dados é amplamente reconhecido pelo INCRA, que ainda utiliza tais imagens. O declínio da vida útil do Landsat-5 atribui mais importância ao lançamento do CBERS-2.
\end{abstract}

Palavras-chave: Sensoriamento remoto, sensores, análise técnica, classificação e análise de agrupamento.

\section{THE USE OF ORBITAL IMAGES AS SUBSIDIES TO AGRARIAN REFORM PROJECTS}

\begin{abstract}
Technical and economical analyses were performed on IKONOS, Landsat TM 5 and Landsat ETM+ 7 and CCD/CBERS data in order to verify their feasibilities to subsidy agrarian reform projects. Results showed that IKONOS data presented excellent technical viability but its high cost prevents its use. Landsat ETM +7 data, with low cost, presented good technical viability, however due to the problems occurring in the satellite operation, its use was also prevented. CCD/CBERS data presented the second best similarity with the ground truth data, although it has presented the small kappa statistic index for the classification. With the launch of the CBERS 2, along with its low cost and possible radiometry correction, it is expected that CCD/CBERS can become a good source of data for agrarian reform projects. Landsat TM 5 data presented the worst technical viability, however, its low cost and potential use as data base is recognized by INCRA, which continues using it as the major source of data for agrarian reform projects.
\end{abstract}

Keywords: Remote sensing, sensors, technical analyses, classification and cluster analysis.

\footnotetext{
${ }^{1}$ Recebido em $1^{\circ} .07 .2004$ e aceito para publicação em 20.04.2005.

${ }^{2}$ Embrapa-Cerrados, BR 020, km 18, Rod. Brasília/Fortaleza. Cx. P. $0822373301-970$ Planaltina-DF.E-mail:<marina@cpac.embrapa.br>. ${ }^{3}$ Departamento de Engenharia Florestal, da UFV, 35571-000 Viçosa-MG. E-mail: <vicente@ ufv.br>.

${ }^{5}$ Departamento de Solos da UFV. E-mail: <elpidio@ solos.ufv.br>.

${ }^{6}$ INCRA/SR 28. INCRA/SR 28 SIG, Q4, Bloco A, Lotes 417/515, Setor de Indústrias Gráficas. 70610-400 Brasília- DF. E-mail: <ricardop@incra.gov.br.>
} 


\section{INTRODUÇÃO}

O Instituto Nacional de Colonização e Reforma Agrária (INCRA) utiliza, com certa tradição, imagens do sensor TM (Thematic Mapper) do satélite Landsat 5 e, mais recentemente, as do sensor ETM+(Enhanced Thematic Mapper Plus) do satélite Landsat 7, como base para estudos de recursos naturais e elaboração de anteprojetos de parcelamento.

Apesar da resolução temporal, dos custos e da facilidade de obtenção das imagens TM/Landsat 5, estas apresentam limitações relacionadas à resolução espacial, principalmente em se tratando de imóveis rurais de tamanho reduzido.

O avanço tecnológico alcançado até 1996, reduzindo em até 10 vezes o custo de produção dos satélites de observação da Terra, e a abertura do mercado a empresas do setor privado têm disponibilizado ao mercado novos produtos e preços cada vez mais acessíveis.

Diante da realidade do mercado em relação aos novos produtos e aos custos de aquisição, permitindo novas possibilidades e opções de uso, torna-se necessário um estudo da viabilidade técnica e econômica dos produtos gerados nos vários campos de aplicação.

Em face da realidade econômica do país e, em particular, à do INCRA, estudar a viabilidade técnica e econômica do emprego de dados provenientes dos novos satélites pode significar aliar qualidade técnica e recursos orçamentários limitados, e, ainda, promover a interação de fenômenos e feições ambientais com fatos e fenômenos de ordens econômica e social, comuns em assentamentos, de acordo com Rindfuss e Stein (1998) e Vilela (2002).

Em virtude da nova realidade do mercado, da escassez de recursos financeiros, da necessidade de uma base de dados confiável tanto em qualidade quanto em quantidade, neste trabalho analisaram-se técnica e economicamente os dados obtidos pelos sensores a bordo dos satélites Landsat-5, Landsat-7, CBERS (China Brazil Earth Resource Satellite) e IKONOS, para fins de reforma agrária.

\section{MATERIAL E MÉTODOS}

\subsection{Base de dados}

Para análises técnica e econômica foram utilizadas imagens dos satélites Landsat-5, Landsat-7, CBERS e IKONOS. Os dados de referência para dar suporte às análises foram obtidos por receptores GPS, operando de modo autônomo.

\subsection{1. Área de estudo}

As cenas analisadas correspondem à área do Projeto de Assentamento Quebra Anzol, localizado no município de Serra do Salitre, Minas Gerais (Figura 1).

O Projeto de Assentamento localiza-se em uma área de clima Cwa predominante, temperado chuvoso, com inverno seco e verão chuvoso e ocorrência de veranicos nos meses de janeiro e, ou, fevereiro, segundo a classificação de Köppen. A precipitação média anual é de $1.600 \mathrm{~mm}$, o déficit hídrico anual estimado da ordem de $150 \mathrm{~mm}$ anuais, a temperatura média mínima de $14,5^{\circ} \mathrm{C}$ e a média máxima de $24,8^{\circ} \mathrm{C}$, com altitude variando de 850 a 970 m; a vegetação predominante é o Cerrado, com suas diversas fitofisionomias já antropizadas.

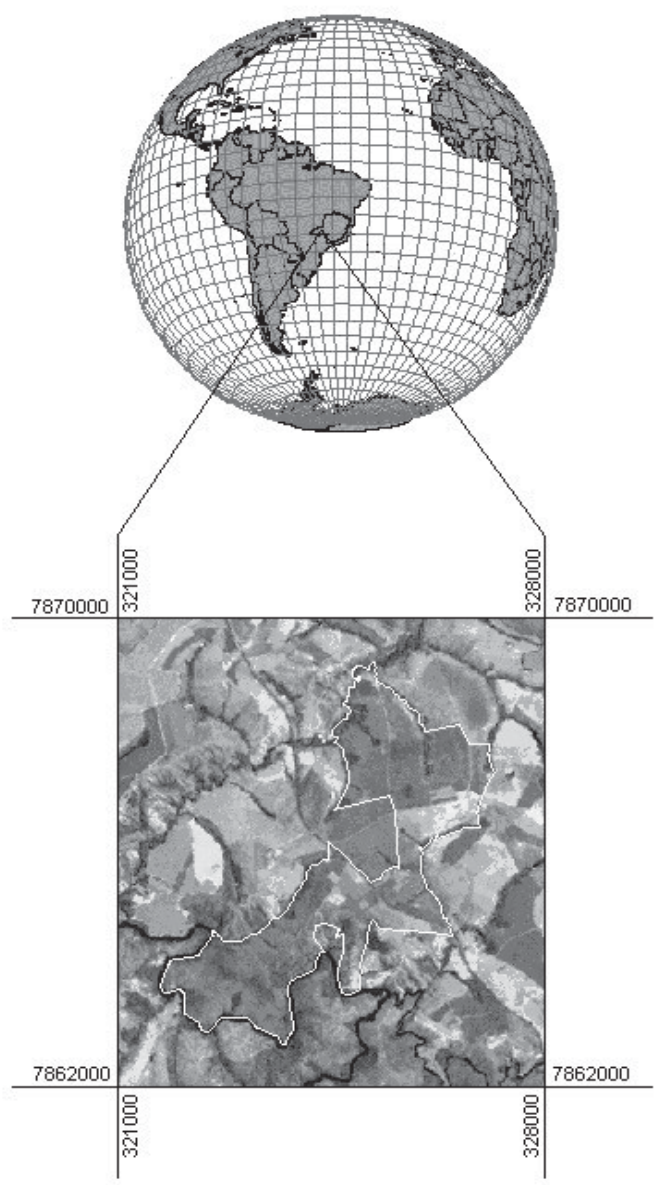

Figura 1 - Localização do Projeto de Assentamento Quebra Anzol.

Figure 1 -Quebra Anzol Settlement Project localization. 
As datas de aquisição das imagens são diferenciadas em função de variáveis ambientais, técnicas e econômicas.

As informações e características dos sensores a bordo dos satélites são apresentadas no Quadro 1 .

\subsection{Fusão do canal pancromático com os canais multiespectrais do sensor ETM+ do Landsat 7}

Para atenuar as limitações da resolução espacial dos canais multiespectrais, efetuou-se a fusão destes com o pancromático, utilizando o programa Fusão-PanMultiespectral $^{6}$.

O programa calcula a média dos valores dos 4 pixels da banda pancromática, que equivalem a 1 pixel da banda multiespectral, bem como a diferença entre cada pixel e a média. Na sequiência, a média da banda pancromática é substituída pelo valor do pixel da banda multiespectral, e as diferenças dos pixels da banda pancromática são inseridas em cada pixel. Assim, têmse as mesmas diferenças de valores entre os pixels da banda pancromática, mas com uma média igual à da banda multiespectral e com resolução espacial igual à banda pancromática.

\subsection{Correção geométrica das imagens digitais}

A correção geométrica das imagens efetuada pelo programa Idrisi 32, conforme informações de Eastman (1997), Veronese (1997), Cook e Pinder (1996) e Kardoulas et al. (1996), envolveu três etapas:

a) Obtenção de coordenadas de pontos de controle terrestre através de receptores GPS GARMIN II e GARMIN Etrex Legend, operando em modo autônomo, com precisão aproximada de $10 \mathrm{~m}$.

b) Interpolação espacial da imagem empregando os pontos de controle terrestre para ajuste de equações polinomiais de primeira ordem (linear).

c) Interpolação da intensidade de brilho utilizando o método do vizinho mais próximo, o qual não altera o valor de brilho dos pixels (JENSEN, 1996), evitandose problemas relacionados à discriminação de feições terrestres em processos de classificação de imagem.

\subsection{Classificação das imagens digitais}

A coleta de amostras de treinamento foi efetuada mediante o levantamento de campo efetuado em data próxima à de aquisição de cada uma das imagens, uma vez que o comportamento da vegetação e o uso do solo variam ao longo do ano. A variação no comportamento da vegetação promoveu diferenças entre as classes representativas da variabilidade local, como mostrado no Quadro 2.

As amostras coletadas treinaram o algoritmo de máxima verossimilhança fornecido pelo programa Idrisi 32, segundo Eastman (1997), o qual foi aplicado às combinações das bandas 3, 4 e 5 dos satélites Landsat5 e Landsat-7 e bandas 4, 3 e 2 do CBERS.

Por falta de um classificador que atendesse às especificações da imagem IKONOS, a sua classificação foi efetuada através de interpretação visual com digitalização em tela das feições identificadas.

Quadro 1 - Informações e características das imagens e sensores utilizados Table 1 - Information and characteristics about the images and sensors

\begin{tabular}{|c|c|c|c|c|c|}
\hline Plataforma & Sensor & $\begin{array}{c}\text { Resolução } \\
\text { Espacial- m - }\end{array}$ & $\begin{array}{c}\text { Resolução } \\
\text { Temporal - dias - }\end{array}$ & $\begin{array}{l}\text { Tamanho da } \\
\text { Cena- km - }\end{array}$ & $\begin{array}{c}\text { Data } \\
\text { de Aquisição }\end{array}$ \\
\hline Landsat 5 & TM & $\begin{array}{l}30-\text { mult. } \\
120-\text { term. }\end{array}$ & 16 & $185 \times 172$ & $10 / 2000$ \\
\hline Landsat 7 & ETM+ & $\begin{array}{l}15 \text { - Pan. } \\
30 \text { - Mult. } \\
60 \text { - term. }\end{array}$ & 16 & $183 \times 172$ & $02 / 2001$ \\
\hline CBERS & $\begin{array}{c}\text { Câmara } \\
\text { CCD }\end{array}$ & 20 & 26 & $134 \times 136$ & $07 / 2001$ \\
\hline$\overline{\text { IKONOS }}$ & IKONOS & $\begin{array}{l}1 \text { - Pan. } \\
4 \text { - Mult. }\end{array}$ & $\begin{array}{l}2,9-\text { Pan. }^{1} \\
1,5-\text { Mult. }^{1}\end{array}$ & $13 \times 13$ & $02 / 2002$ \\
\hline
\end{tabular}

Esses valores valem para latitude de $+/-40^{\circ}$. Para latitudes maiores, a freqüência de revisita é menor, e para as latitudes próximas ao Equador essa freqüência de revisita é maior.

${ }^{6}$ Programa em Fortran para a fusão da banda pancromática com as bandas multiespectrais do sensor ETM+, desenvolvido por Mauro Antônio Homem Antunes, professor da Universidade Federal Rural do Rio de Janeiro. <mantunes@ ufrrj.br>. 
Quadro 2-Classes de variabilidade existente nas imagens

Table 2 - Classes of variability existent in the images

\begin{tabular}{ll}
\hline Imagem & \multicolumn{1}{c}{ Classes de variabilidade } \\
\hline TM/Landsat 5 & $\begin{array}{l}\text { Água, campo limpo, cerrado ralo, mata ciliar/cerradão, pastagem, cascalho, solo exposto/arado, } \\
\text { restos culturais/pastagem } \\
\text { ETM+/Landsat } 7\end{array}$ \\
& Água, campo limpo, cerrado ralo, mata ciliar/cerradão, pastagem, solo exposto/arado, cultura \\
CCD/CBERS & $\begin{array}{l}\text { Água, campo limpo, cerrado ralo, mata ciliar/cerradão, pastagem, cultura agrícola } \\
\text { Água, área agrícola, mata ciliar, cerradão, cerrado, cerrado ralo, campo sujo, campo limpo, } \\
\text { pastagem-grama, batatais, pastagem e restos culturais, pastagem-braquiária, estrada, asfalto, } \\
\text { faixa de domínio do asfalto }\end{array}$ \\
\hline
\end{tabular}

Após a classificação, as imagens dos satélites Landsat 5, Landsat 7 e CBERS foram submetidas a um filtro de moda $3 \times 3$, objetivando-se a eliminação dos pixels isolados, definidos por Lillesand e Kiefer (1994) como aspecto ruidoso.

\subsubsection{Obtenção dos dados de referência}

A exemplo das amostras de treinamento, foi gerado um arquivo de referência para cada uma das imagens classificadas.

Os arquivos de referência foram baseados nos levantamentos de campo em data próxima à de aquisição de cada uma das imagens. Foram levantados, de forma aleatória, 272, 263, 256 e 253 pontos amostrais, para compor os arquivos de referência das imagens TM/ Landsat 5, ETM+/Landsat 7, CCD/CBERS e IKONOS, respectivamente.

\subsubsection{Cálculo dos índices de exatidão das imagens classificadas}

Classificadas as imagens e obtidos os arquivos de referência, procedeu-se aos cruzamentos de tais dados, gerando as matrizes de erros, que possibilitam o cálculo dos índices de Exatidão Global e Kappa, conforme demonstrado por Campbell (1987).

\subsubsection{Significância entre os índices de exatidão das imagens classificadas}

Para a verificação da significância dos índices de exatidão das imagens classificadas, foi utilizado o índice Kappa, o qual representa inteiramente a matriz de confusão, medindo o relacionamento entre a concordância, além da casualidade, e a discordância esperada (BRITES, 1996).

\section{R. Árvore, Viçosa-MG, v.29, n.4, p.627-638, 2005}

A equação que estima o índice Kappa é definida como:

$$
\widehat{k}=\left(\mathrm{P}_{0}-\mathrm{P}_{\mathrm{c}}\right) /\left(1-\mathrm{P}_{\mathrm{c}}\right)
$$

em que:

$\mathrm{P}_{0}=$ proporção de unidades que concordam, ou seja, valor observado ou Exatidão Global; e

$\mathrm{P}_{\mathrm{c}}=$ proporção de unidades que concordam por casualidade, ou seja, valor esperado.

Para calcular a variância do índice Kappa, utilizouse a equação apresentada por Ma e Redmond (1995):

$$
\sigma^{2}(\hat{k})=P_{0}\left(1-P_{0}\right) /\left[N\left(1-P_{c}\right)^{2}\right]
$$

em que:

$\mathrm{P}_{0}=$ proporção de unidades que concordam, ou seja, valor observado ou Exatidão Global;

$\mathrm{N}=$ número total de pixels contemplados pela matriz de erros; e

$\mathrm{P}_{\mathrm{c}}=$ proporção de unidades que concordam por casualidade, ou seja, valor esperado.

A significância da diferença entre os índices de exatidão foi verificada pela aplicação do teste $\mathrm{Z}$ a $99 \%$ de probabilidade, conforme especificado na equação apresentada na sequiência.

$$
\mathrm{Z}=\left(\mathrm{C}_{1}-C_{2}\right) /\left(\sqrt{\sigma_{1}^{2}+\sigma_{2}^{2}}\right)
$$

em que:

$\mathrm{C}_{1}=$ coeficiente de exatidão calculado para a classificação 1;

$\mathrm{C}_{2}=$ coeficiente de exatidão calculado para a classificação 2;

$\sigma_{1}^{2}=$ variância da classificação 1 , e

$\sigma_{2}^{2}=$ variância da classificação 2 . 


\subsection{Avaliação técnica das imagens para fins de reforma agrária}

Após a correção geométrica das imagens, foram digitalizados sobre essas divisas as estradas e os rios do PA Quebra Anzol, dados considerados básicos na elaboração de anteprojeto de parcelamento.

Dos arquivos resultantes do processo de digitalização, foram selecionados pontos de fácil identificação em todas as imagens classificadas, cujas coordenadas foram comparadas com um arquivo de referência obtido em campo pelo INCRA, através de estação total de trabalho.

A comparação entre as imagens e a verdade de campo foi efetuada em duas etapas. Na primeira, as coordenadas dos pontos das imagens e verdade de campo foram submetidas a uma análise de agrupamento, utilizando-se o programa MVSP (multi-Variate Statistical Package) versão 2.1, para verificar a similaridade das imagens com a verdade de campo; na segunda, verificouse a existência de diferença estatística entre as coordenadas das imagens testadas. Aplicou-se o teste de Tukey às diferenças das coordenadas dos pontos das imagens e verdade de campo, nas direções leste e norte, no nível de $95 \%$ de probabilidade, utilizando o programa SYSTAT 6.0.

A análise de agrupamento utilizou como coeficiente de semelhança entre pares de locais a distância euclidiana, que é um coeficiente de dissimilaridade, pois, quanto menor a distância entre dois locais, mais similares eles são, segundo as características consideradas (MARTEL et al., 2004). A distância euclidiana foi aplicada aos pares de coordenadas dos pontos das imagens classificadas e os pontos compondo o arquivo de referência, nas direções leste e norte.

\subsection{Análise dos custos de aquisição das imagens digitais}

Uma análise foi efetuada, comparando-se os custos de aquisição, por $\mathrm{km}^{2}$, das imagens obtidas pelos diferentes sensores.

A análise de custos desempenha, juntamente com a avaliação técnica da imagem, função determinante na escolha do sensor que fornecerá a base de dados mais adequada aos objetivos do trabalho e aos recursos financeiros disponíveis, ou seja, estabelece uma relação custo/benefício na escolha da base de dados.

\section{RESULTADOS E DISCUSSÃO}

\subsection{Correção geométrica das imagens digitais}

As imagens corrigidas apresentaram os seguintes valores de raiz quadrada do erro médio quadrático de 15,3 m, 6,0 m, 7,4 m e 1,2 m, nas imagens TM/ Landsat 5, ETM+/Landsat 7, CCD/CBERS e IKONOS, respectivamente.

\subsection{Classificação das imagens digitais}

As combinações das bandas 3, 4 e 5 dos satélites Landsat-5 e Landsat-7 e bandas 4, 3 e 2 do CBERS, submetidas ao algoritmo de classificação de máxima verossimilhança e pós-filtradas, são apresentadas nas Figuras 2, 3 e 4, respectivamente, e a imagem IKONOS, submetida à classificação visual, na Figura 5.

Na classificação supervisionada das imagens dos satélites Landsat-5, Landsat-7 e CBERS, as diferentes datas de aquisição propiciaram a discriminação de algumas feições. O melhor exemplo deu-se com a feição cascalho, presente em maior ou menor quantidade no solo e muito bem discriminado na imagem TM/Landsat-5.

A boa discriminação da feição cascalho através da imagem TM/Landsat-5 deve-se à interação da data de aquisição da imagem, correspondendo ao final da estação seca, com a fitofisionomia campo limpo nas áreas de cascalho.

A fitofisionomia campo limpo, composta predominantemente por gramíneas com poucas espécies arbustivas (Figuras 5 e 6), aliada à estação seca, expõe preponderantemente o solo, resultando numa resposta espectral diferenciada.

Embora a vegetação campo limpo seja discriminada na imagem ETM+/Landsat-7, a data de aquisição desta corresponde à estação chuvosa, período em que a vegetação se torna mais densa, recobrindo o solo e o cascalho.

Embora a imagem CCD/CBERS tenha sido adquirida durante a estação seca, o período de estiagem do ano de 2001 foi menos rigoroso que o de $2000^{8}$, o que pode ter afetado a discriminação das áreas de cascalho.

Outra desvantagem do CCB/CBERS deve-se ao fato de o sensor possuir bandas nos canais 2, 3 e 4, em que os canais 2 e 3 são bastante correlacionados, ao contrário das bandas 3, 4 e 5 dos sensores TM e ETM+.

\footnotetext{
${ }^{8}$ Conforme observações de campo e informações fornecidas pelos assentados.
} 


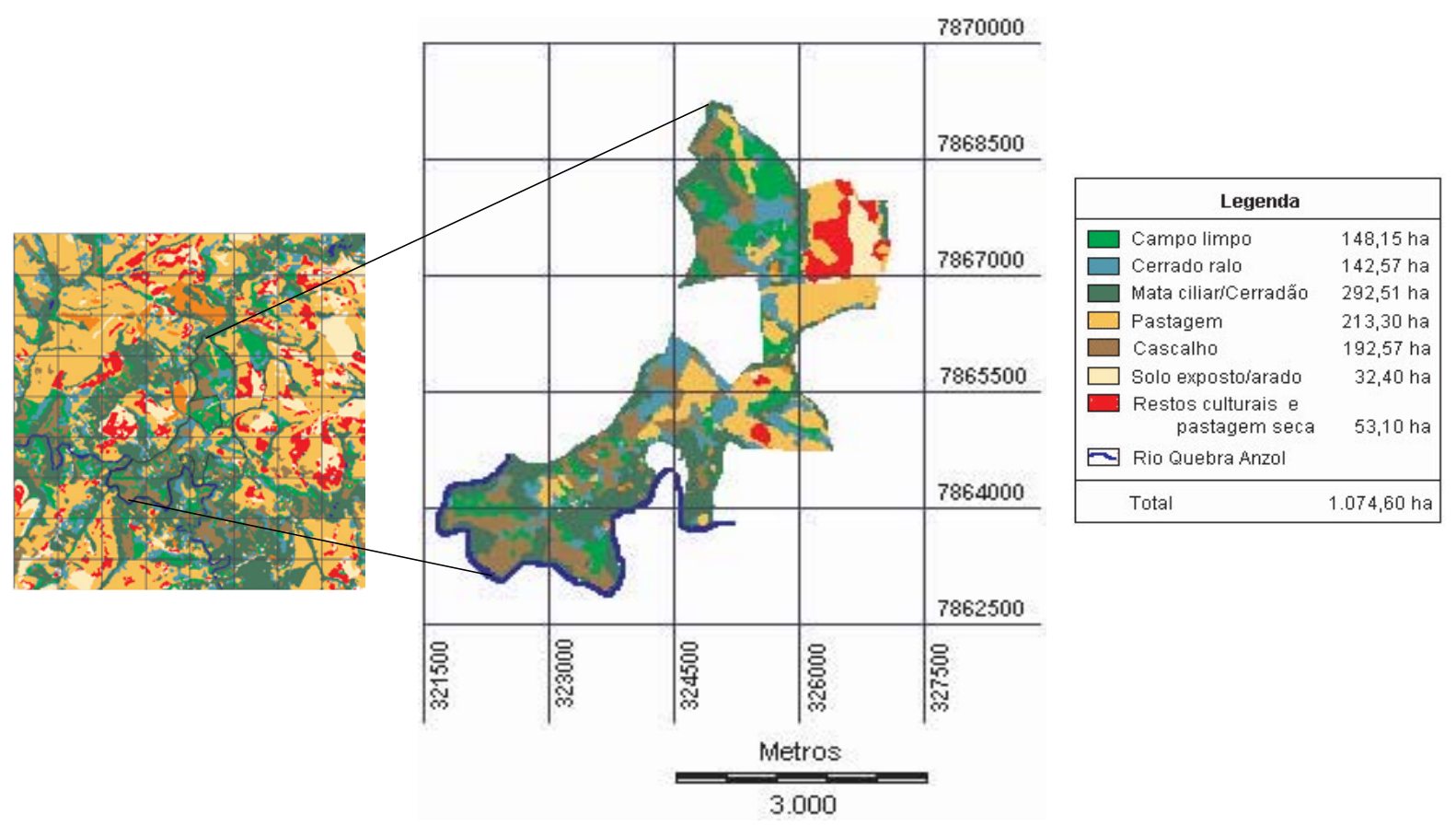

Figura 2 - Combinações das bandas 3, 4 e 5 do sensor TM do satélite Landsat-5, classificada e pós-filtrada. Figure 2-Combination of bands 3, 4 and 5 of TM/Landsat-5, classified and post-filtered.
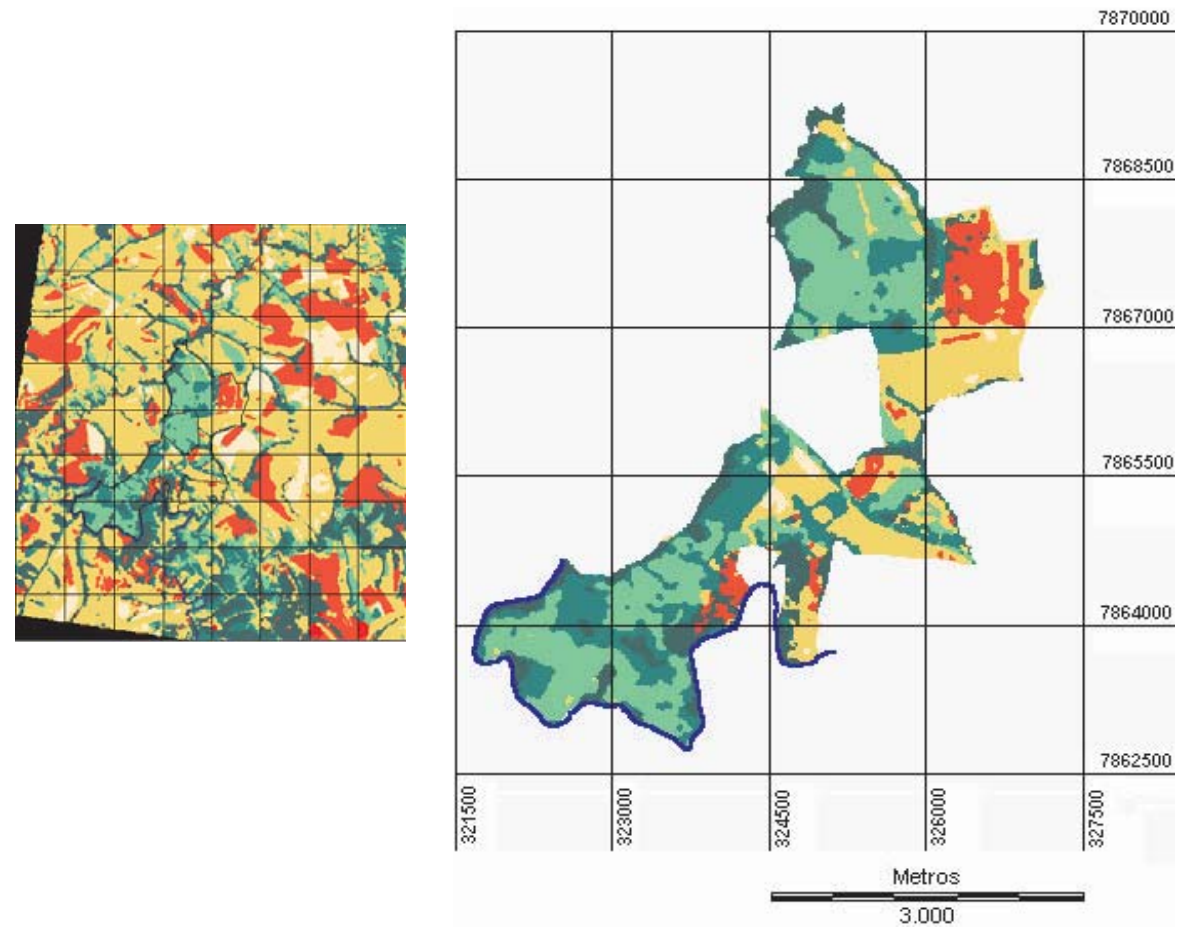

\begin{tabular}{|lr|}
\hline \multicolumn{2}{|c|}{ Legenda } \\
\hline$\square$ Campo limpo & $341,54 \mathrm{ha}$ \\
\hline Cerrado ralo & $250,68 \mathrm{ha}$ \\
\hline Solo exposto / arado & $14,17 \mathrm{ha}$ \\
$\square$ Cultura Agrícola & $87,26 \mathrm{ha}$ \\
$\square$ Mata ciliar / Cerradẫo & $159,84 \mathrm{ha}$ \\
\hline Pastagem & $220,31 \mathrm{ha}$ \\
\hline Rio Quebra Anzol \\
\hline Total \\
\hline
\end{tabular}

Figura 3 - Combinações das bandas 3, 4 e 5 do sensor ETM+ do satélite Landsat-7, classificada e pós-filtrada. Figure 3 -Combination of bands 3, 4 and 5 of ETM+/Landsat-7, classified and post-filtered.

R. Árvore, Viçosa-MG, v.29, n.4, p.627-638, 2005 


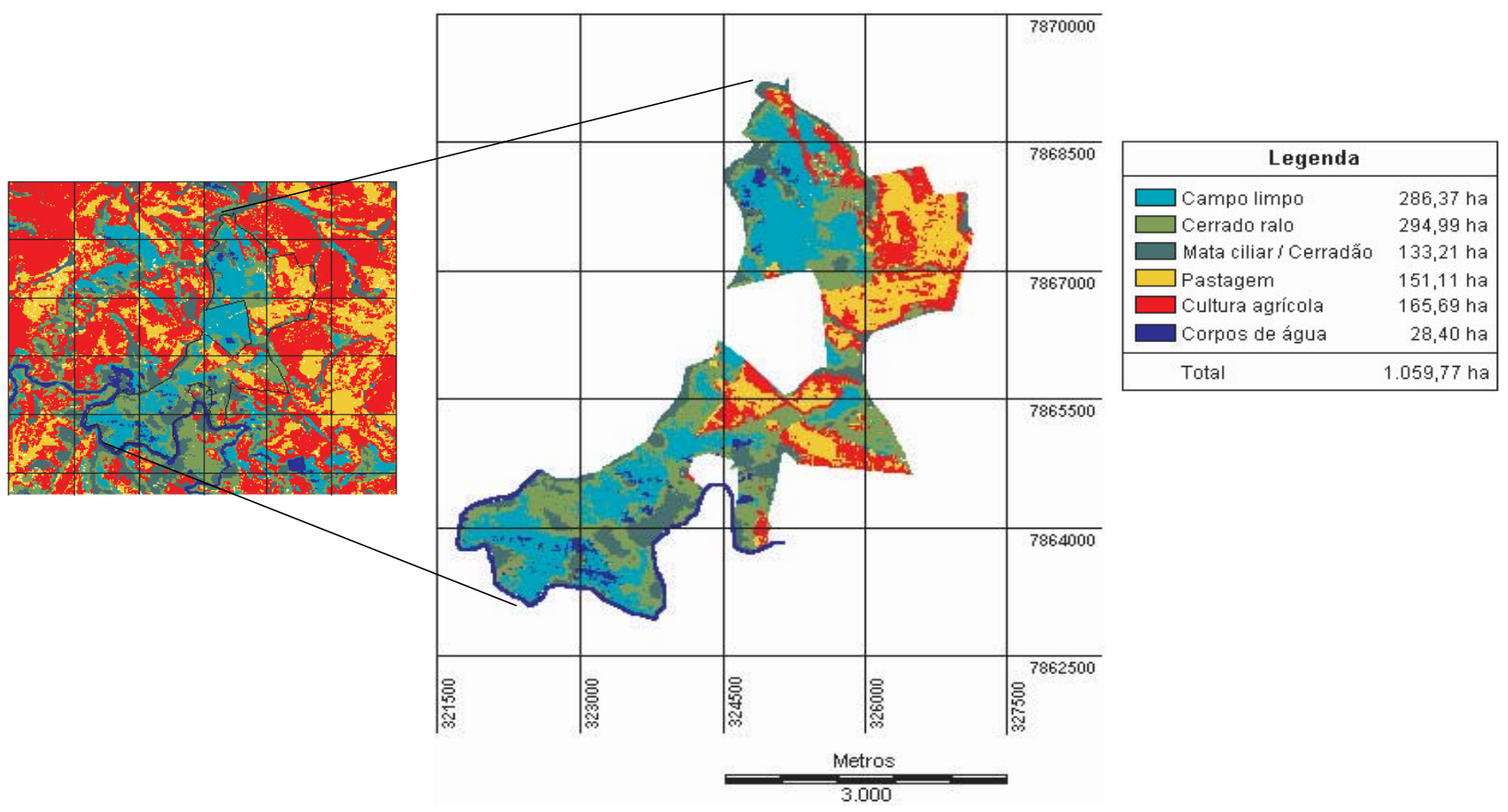

Figura 4 - Combinações das bandas 4, 3 e 2 da câmara CCD do satélite CBERS, classificada e pós-filtrada. Figure 4-Combination of bands 4, 3 and 2 of CCD/CBERS, classified and post-filtered.

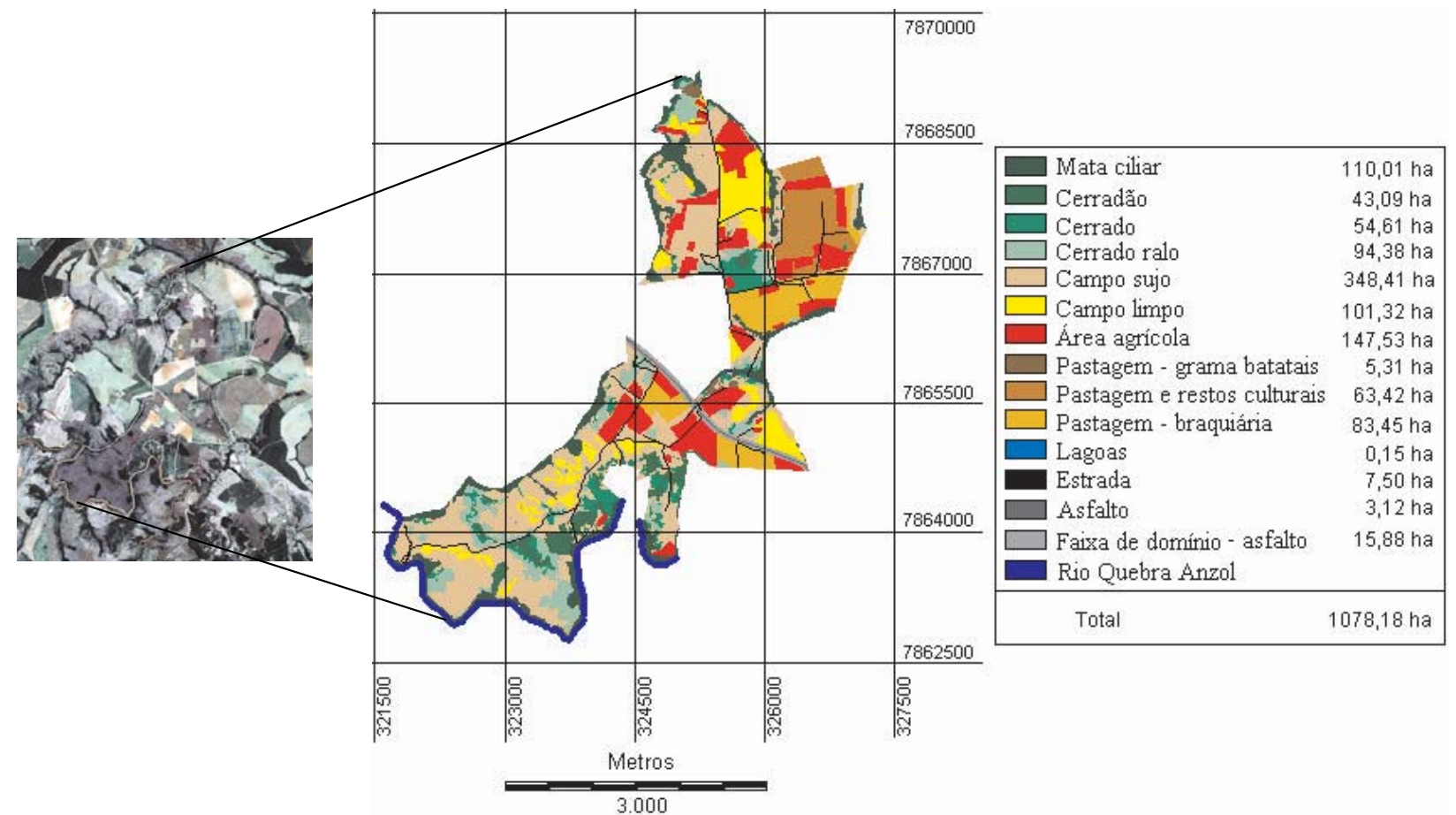

Figura 5 - Combinação das bandas 1, 2 e 3 do sensor IKONOS, classificada visualmente.

Figure 5 -Combination of bands 1, 2 and 3 of IKONOS, visually classified. 


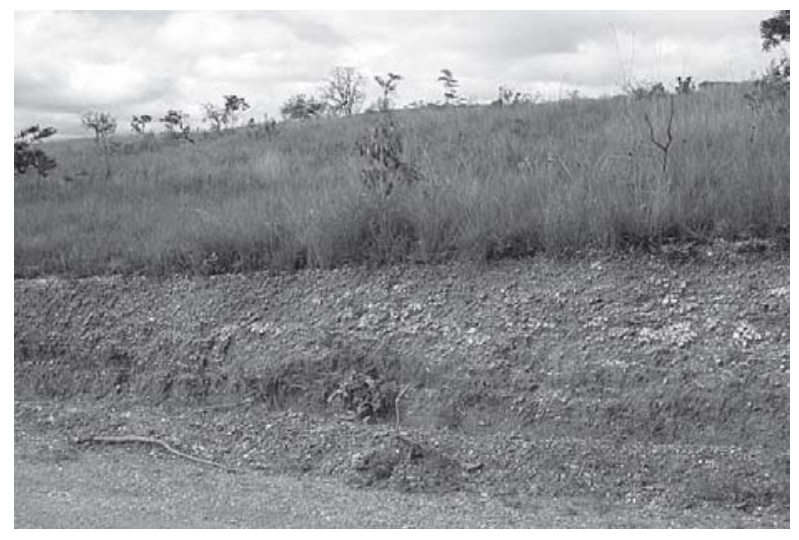

Figura 6 - Cascalho sob vegetação herbáceo-arbustiva. Figure 6-Bush and grass vegetation above gravel.

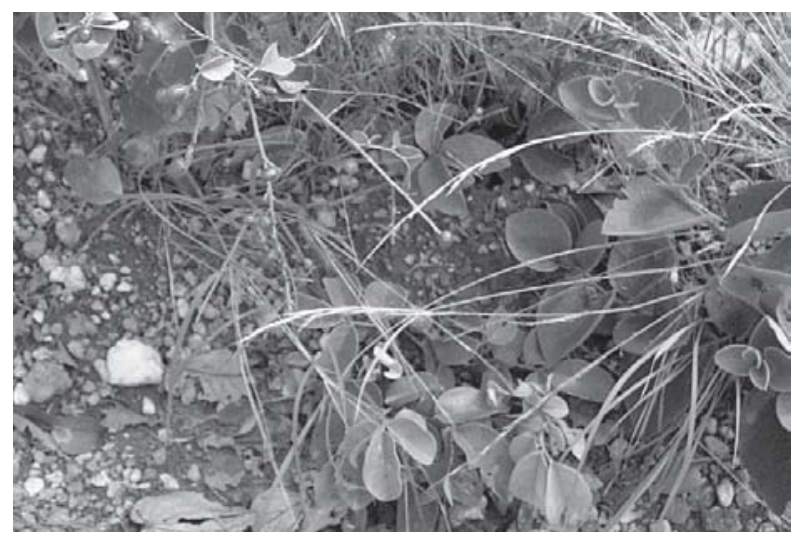

Figura 7 - Vegetação herbáceo-arbustiva expondo o solo e o cascalho.

Figure 7 -Bush and grass vegetation exposing the soil and gravel.

Problemas de radiometria existentes na imagem CCD/CBERS dificultaram a seleção das amostras de treinamento e interferiram diretamente no nível de brilho das amostras e imagem, dificultando, por conseguinte, o desempenho do classificador e a exatidão da imagem.

A interferência dos problemas de radiometria no processo de classificação pode ser verificada na composição das bandas 4, 3 e 2, submetida ao algoritmo de classificação de máxima verossimilhança pós-filtrada (Figura 4), em que observaram-se problemas de discriminação em relação às classes Água e Campo limpo, além dos pixels isolados evidenciados na imagem classificada não submetida ao processo de filtragem (Figura 8).

R. Árvore, Viçosa-MG, v.29, n.4, p.627-638, 2005

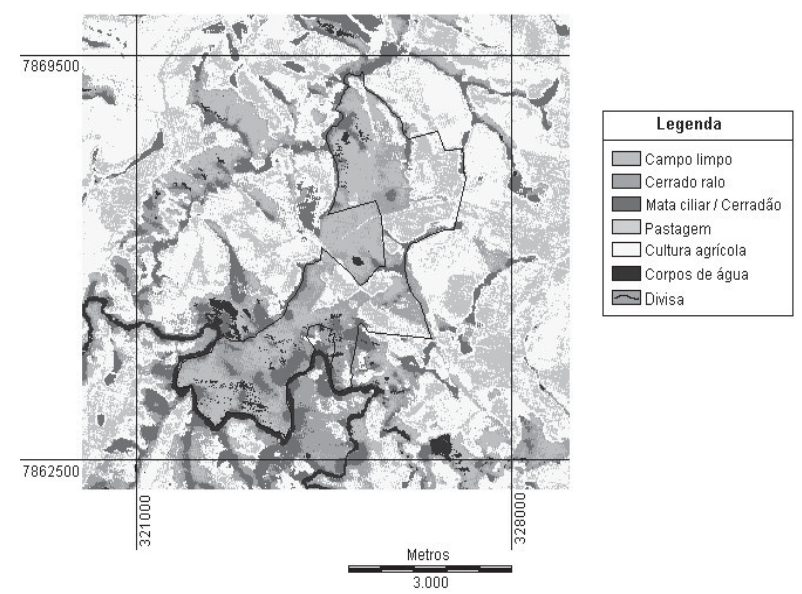

Figura 8 - Composição das bandas 4, 3 e 2, do CCD/CBERS, classificada e não filtrada.

Figure 8-Combination of bands 4, 3 and 2 of CCD/CBERS, classified and non-filtered.

Em conseqüência das características da imagem IKONOS, na classificação visual se obtiveram melhores resultados em relação à discriminação e número de classes, em comparação com as demais imagens analisadas. Isso é devido ao fato de a resposta espectral de cada pixel componente da imagem IKONOS corresponder a uma área de $16 \mathrm{~m}^{2}$, enquanto nas imagens Landsat 5, Landsat 7 e CBERS a área é de 900, 225 e $400 \mathrm{~m}^{2}$, respectivamente. Portanto, a resolução espacial da imagem IKONOS, além de discriminar mais precisamente as feições, minimiza os efeitos relacionados à saturação de pixels adjacentes, permitindo a delimitação mais precisa dos limites das feições (Figura 9).

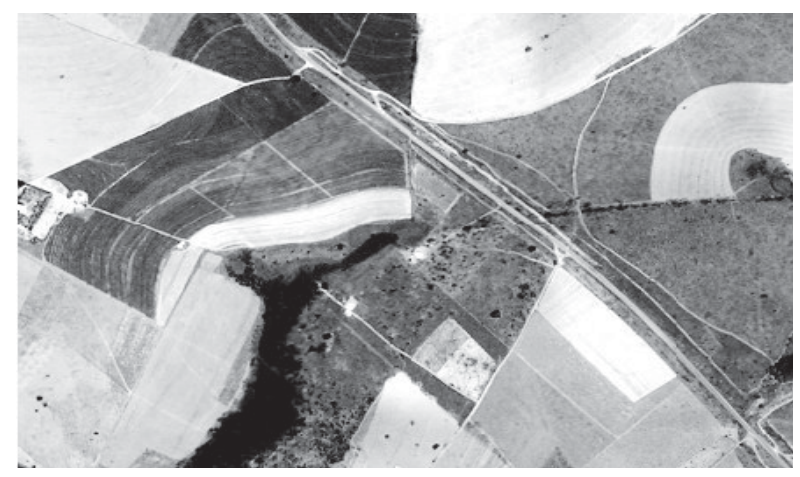

Figura 9-Composição das bandas 1, 2 e 3 do sensor IKONOS, mostrando a boa discriminação das feições terrestres.

Figure 9 - Combination of bands 1, 2 and 3 of IKONOS showing the good discrimination of terrestrial objects. 
Outra vantagem da classificação visual refere-se à possibilidade de o intérprete analisar outros elementos de fotointerpretação como cor, textura, forma e tamanho, dentre outros, realçados pela resolução espacial do IKONOS.

\subsection{1. Índices de exatidão das imagens classificadas}

Os índices Exatidão Global e Kappa das imagens classificadas, calculados a partir das matrizes de erros, estão apresentados no Quadro 3, sendo as diferenças entre os índices Exatidão Global e Kappa decorrentes da eliminação da concordância, em razão da casualidade dos cálculos do índice Kappa (BRITES, 1996).

\subsubsection{Significância entre os índices de exatidão das imagens classificadas}

Os níveis de significância entre os índices de exatidão verificada pela aplicação do teste Z a $99 \%$ de probabilidade estão apresentados no Quadro 4.

A classificação da imagem IKONOS apresentou melhor desempenho na discriminação de feições, em

Quadro 3 - Índice Exatidão Global e Kappa das imagens classificadas

Table 3 - Global accuracy and Kappa index for classified images

\begin{tabular}{lcccc}
\hline Imagem & \multicolumn{2}{c}{ Não filtrada } & \multicolumn{2}{c}{ Pós-filtrada } \\
\cline { 2 - 5 } & $\begin{array}{c}\text { Exatidão } \\
\text { Global }\end{array}$ & Kappa & $\begin{array}{c}\text { Exatidão } \\
\text { Global }\end{array}$ & Kappa \\
\hline IKONOS & 93,73 & 92,93 & - & - \\
ETM+/Landsat 7 & 87,07 & 84,70 & 89,73 & 87,87 \\
TM/Landsat 5 & 79,04 & 76,05 & 77,97 & 74,80 \\
CCD/CBERS & 77,34 & 72,74 & 78,51 & 74,14 \\
\hline
\end{tabular}

comparação com as classificações das imagens do ETM+/Landsat 7, TM/Landsat 5 e CCD/CBERS, observando-se que o processo de pós-filtragem utilizando um filtro de moda $3 \times 3$, embora tenha imprimido melhor qualidade visual à imagem classificada, não promoveu alteração significativa na sua exatidão.

O desempenho da classificação visual da imagem IKONOS deveu-se basicamente à qualidade da imagem e à resolução espacial desta em oposição à resolução espacial das demais imagens e aos problemas de radiometria presentes na imagem do CCD/CBERS.

\subsection{Avaliação técnica das imagens para fins de reforma agrária}

As coordenadas dos pontos de referência e dos pontos selecionados em cada uma das imagens são apresentadas no Quadro 5 e os resultados da análise de agrupamento, no Quadro 6.

Verificou-se que a imagem IKONOS apresentou maior similaridade com a referência ou verdade de campo, a qual decresce do CBERS para as plataformas Landsat, pois a distância euclidiana aumenta, ou seja, quanto maior a distância euclidiana, menor a similaridade entre os dados.

O resultado do teste de Tukey indicou que as coordenadas provenientes das imagens CBERS e Landsats 5 e 7 são estatisticamente iguais no nível de $95 \%$ de probabilidade, nas direções leste e norte, e as coordenadas obtidas da imagem IKONOS são estatisticamente diferentes das coordenadas provenientes das demais imagens no sentido norte (Figura 10).

Quadro 4 - Níveis de significância entre os índices Kappa das classificações geradas, no nível de 99\% de probabilidade, pelo teste $\mathrm{Z}$

Table 4 - Significance levels of Kappa indexes for classified images, using Z test at 99\% of probability

\begin{tabular}{|c|c|c|c|c|c|c|c|}
\hline \multirow[t]{2}{*}{ Imagens } & & \multicolumn{2}{|c|}{ TM/Landsat 5} & \multicolumn{2}{|c|}{ ETM+/Landsat 7} & \multicolumn{2}{|c|}{ CCD/CBERS } \\
\hline & & Filtrada & $\begin{array}{c}\text { Não- } \\
\text { Filtrada }\end{array}$ & Filtrada & $\begin{array}{c}\text { Não- } \\
\text { Filtrada }\end{array}$ & Filtrada & $\begin{array}{c}\text { Não- } \\
\text { Filtrada }\end{array}$ \\
\hline$\overline{\mathrm{TM}}$ & Filtrada & $\longrightarrow$ & & & & & \\
\hline Landsat 5 & Não-filtrada & NS & $\longrightarrow$ & & & & \\
\hline ETM+ & Filtrada & $(* *)$ & $(* *)$ & - & & & \\
\hline Landsat 7 & Não-filtrada & $(*)$ & $(*)$ & NS & - & & \\
\hline CBERS & Filtrada & NS & NS & $(* *)$ & $(* *)$ & - & \\
\hline & Não-filtrada & NS & NS & $(* *)$ & $(* *)$ & NS & \\
\hline IKONOS & & $(* *)$ & $(* *)$ & $(* *)$ & $(* *)$ & $(* *)$ & $(* *)$ \\
\hline
\end{tabular}

NS: não-significativo a $1 \%,(*)$ : significativo a $5 \%$ e (**): Significativo a $1 \%$.

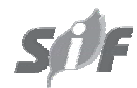

R. Árvore, Viçosa-MG, v.29, n.4, p.627-638, 2005 


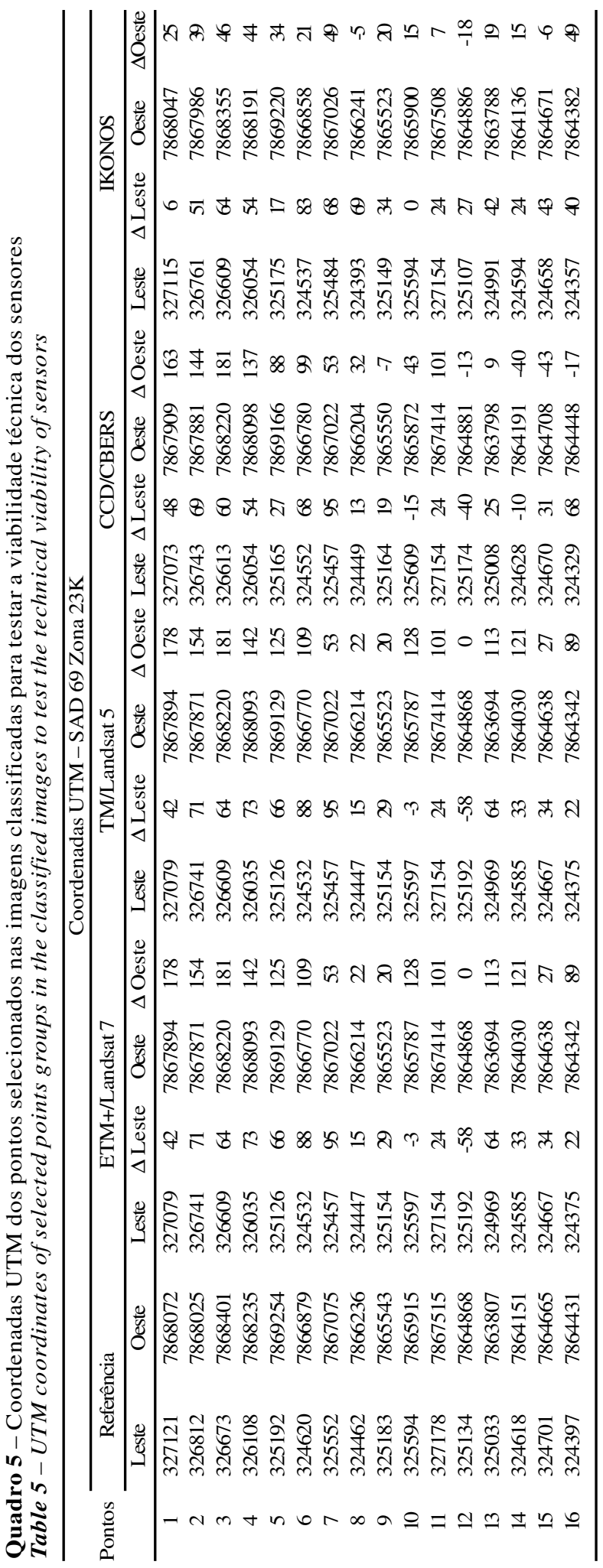

Quadro 6 - Distância euclidiana resultante da análise de agrupamento - metros

Table 6 - Euclidean distance resulted from cluster analysis -meters

\begin{tabular}{lcccc}
\hline Verdade & \multicolumn{4}{c}{ Imagens } \\
\cline { 2 - 5 } & IKONOS & CBERS & Landsat-7 & Landsat-5 \\
\hline Verdade - & 185,6394 & 192,8730 & 221,7995 & 221,7995 \\
Leste & & & & \\
Verdade - & 243,5098 & 407,2972 & 481,4156 & 481,4156 \\
Norte & & & & \\
\hline
\end{tabular}
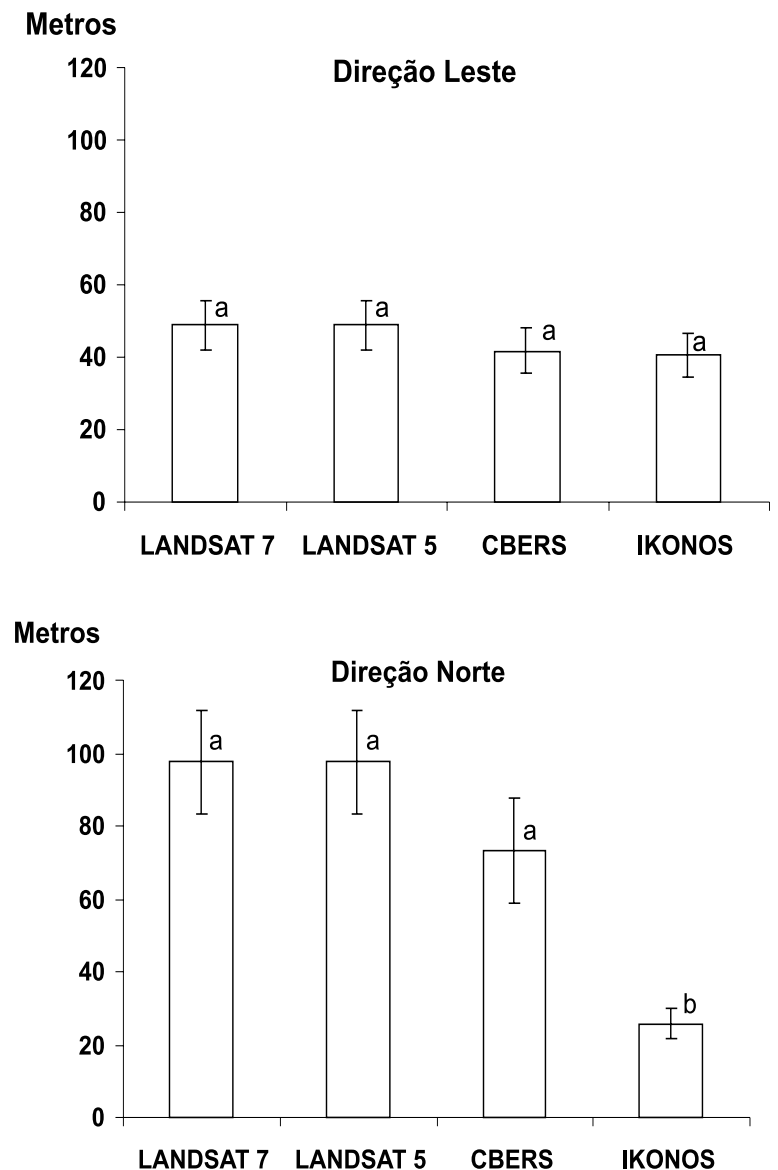

Figura 10 - Média das diferenças de coordenadas obtidas das imagens e verdade de campo. As médias seguidas por uma mesma letra não diferem significativamente no nível de $95 \%$ de probabilidade pelo teste de Tukey. As linhas verticais representam o erro-padrão.

Figure 10-Mean of coordinate differences obtained from images and ground truth. Means followed by the same letter are significant at $95 \%$ level of probability by Tukey's test. Vertical lines represent the standard deviation. 
Verificou-se que tanto a média das diferenças quanto o erro-padrão são consideravelmente menores na imagem IKONOS no sentido norte, em comparação com as demais imagens. No entanto, o mesmo não se observou com as coordenadas no sentido leste (Figura 10). Essa divergência pode ser resultante do arquivo de referência utilizado, uma vez que sobre ele não houve controle direto da equipe que desenvolveu o presente trabalho.

Os resultados indicaram que a imagem IKONOS apresenta melhor desempenho para fins de reforma agrária ou outro que necessite de discriminação de feições, levantamento dos recursos naturais e mapeamentos diversos.

A imagem Landsat 7, embora não tenha apresentado maior similaridade com a verdade, tem o segundo melhor índice Kappa da classificação, devido à qualidade dos dados e à possibilidade de fusão da banda pancromática com as bandas multiespectrais. Dessa forma, podese considerar que, depois da imagem IKONOS, a imagem Landsat 7 apresentou os melhores resultados para fins de reforma agrária ou outro, cujos objetivos principais sejam a discriminação de feições e a delimitação de áreas. Entretanto, a perda do contato com a plataforma Landsat 7 inviabilizou a aquisição de novas imagens do sensor ETM+.

Apesar de a imagem CBERS ter apresentado maior similaridade com a verdade de campo em comparação com as imagens TM/Landsat-5 e ETM+/Landsat-7, o índice Kappa da classificação é baixo, encerrando erros que podem inviabilizar sua utilização na discriminação de feições. Salienta-se que o levantamento bem feito da área foi decisivo no respaldo à classificação da imagem CCD/CBERS.

Embora a resolução espacial do CBERS não seja tão refinada quanto à resolução de outros produtos existentes no mercado, o seu preço constitui fator a ser considerado em qualquer análise, podendo o lançamento do CBERS 2 preencher a lacuna resultante da perda do contato com o satélite Landsat 7.

Deve-se salientar, ainda, que o processo de correção geométrica das imagens constituiu uma etapa decisiva na precisão das imagens e, conseqüentemente, na precisão das coordenadas dos pontos selecionados.

\subsection{Custos de aquisição das imagens digitais}

A análise dos custos de aquisição das imagens dos diferentes sensores está apresentada no Quadro 7.
Quadro 7-Custos de aquisição das imagens obtidas pelos sensores a bordo dos satélites Landsat-5, Landsat-7, CBERS e IKONOS

Table 7 -Costs of images obtained from TM/Landsat-5, ETM+/ Landsat-7, CCD/CBERS and IKONOS satellites

\begin{tabular}{lcccc}
\hline & $\begin{array}{c}\text { TM/ } \\
\text { Landsat-5 }\end{array}$ & $\begin{array}{c}\text { ETM+/ } \\
\text { Landsat-7 }\end{array}$ & CBERS & IKONOS \\
\hline $\begin{array}{l}\text { Custo de aquisição } \\
-\mathrm{R} \$ / 100 \mathrm{~km}^{2}\end{array}$ & 3,14 & 3,45 & 2,74 & $6.000,00$ \\
\hline
\end{tabular}

\section{CONCLUSÕES}

A partir dos resultados e da situação do mercado, pode-se inferir que:

a) O melhor desempenho diante das análises técnicas efetuadas foi obtido, respectivamente, pelas imagens IKONOS, ETM+/Landsat 7, CCD/CBERS e TM/Landsat 5.

b) O custo da imagem IKONOS pode inviabilizar o seu emprego para fins de reforma agrária, restringindose às atividades que requerem alto nível de detalhamento do uso do solo, laudos periciais e vistorias ou outra envolvendo questões judiciais de natureza delicada e complexa.

c) A imagem ETM+/Landsat 7, com baixo custo de aquisição, apresentou grande viabilidade técnica para fins de reforma agrária, porém a perda do contato com a plataforma Landsat 7 inviabilizou a aquisição de novas imagens do sensor ETM+.

d) As imagens do CBERS 2 podem constituir um grande potencial na coleta de dados para fins de reforma agrária, ou outro, principalmente se os problemas de radiometria existentes no primeiro CBERS forem sanados pelos pesquisadores brasileiros para a atual plataforma.

e) Embora o TM/Landsat 5 tenha apresentado o mais baixo desempenho técnico nas análises efetuadas, o seu potencial como base de dados é reconhecido pelo INCRA, que ainda utiliza tais imagens. No entanto, a vida útil do Landsat 5 começa a declinar, pois está em operação desde março de 1984, fato que pode atribuir mais importância ao lançamento do CBERS 2.

\section{AGRADECIMENTOS}

Ao INCRA e à Universidade Federal de Viçosa, por permitirem a realização deste trabalho; ao $\mathrm{CNPq}$, à FAPEMIG e à CAPES, pelo apoio financeiro dado ao projeto; e ao INPE, pela cessão da imagem CCD/CBERS.

R. Árvore, Viçosa-MG, v.29, n.4, p.627-638, 2005 


\section{REFERÊNCIAS BIBLIOGRÁFICAS}

BRITES, R. S. Verificação de exatidão em classificação de imagens orbitais: efeitos de diferentes estratégias de amostragem e avaliação de índices de exatidão. 1996. 101f. Tese (Doutorado em Ciências Florestais) - Universidade Federal de Viçosa, Viçosa, 1996.

CAMPBELL, J. B. Introduction to remote sensing. New York: The Guilford, 1987. 551p.

COOK, A. E.; PINDER, J. E. Relative accuracy of rectification using coordinates determined from maps and the global positioning system.

Photogrammetric Engineering and Remote Sensing, v.62, n.1, p.73-77, 1996.

EASTMAN, J.R. Idrisi for windows: user's guide; version 2.0. Worcester: Clark University, 1997. Paginação Irregular.

JENSEN, J. R. Introductory digital image processing: a remote sensing perspective. 2 . ed. New Jersey: Prentice Hall, 1996. 316p.

KARDOULAS, N.G.; BIRD, A. C.; LAWAN, A. I. Geometric correction of SPOT and Landsat image: a comparison of map and GPS derived control points. Photogrammetric Engineering and Remote Sensing, v.62, n.10, p.1173-1177, 1996.

LILLESAND, T.M.; KIEFER, R.W. Remote sensing and image interpretation. 2. ed. Chichester: John Willey \&Sons, 1994. 740p.
MA, Z.; REDMOND, R. L. Tau coefficents for accuracy assessment of classification of remote sensing data. Photogrammetric Engineering and Remote Sensing, v.61, n.4, p. 435-439, 1995.

MARTEL J. H. I. et al. Estatística multivariada na discriminação de raças amazônicas de pupunheiras (Bactris gasipaes Kunth) em Manaus (Brasil). Revista Brasileira de Fruticultura. Disponível em:<http://www.scielo.br/ scielo.php?script $=$ sci_arttext\&pid=S0100$29452003000100033>$ Acesso em 09 set. de 2004.

RINDFUSS, R.R.; STERN, P.C. Linking remote sensing and social science: the need and the challenges. In: LIVERMAN, D. et al. (Eds.) People and Pixels: linking remote sensing and social science. Washington, DC: National Academic Press, 1998. p.1-27.

VERONESE, V. F.; LINS, H. B.; FERREIRA, M. C. O uso de GPS para correção geométrica de imagens de satélite: uma análise comparativa. In: GIS BRASIL, 97., 1997, Curitiba. Anais...

Curitiba: 1997. CD-ROM.

VILELA, M. F Integração de técnicas de geoprocessamento e levantamento participativo de informações socioambientais: um subsídio para a reforma agrária. 2002. 135f. Tese (Doutorado em Ciências Florestais) - Universidade Federal de Viçosa, Viçosa, 2002. 